\title{
Микотоксикозы
}

\section{ЭКСПРЕССИЯ ГЕНОВ, АССОЦИИРОВАННЫХ С ИММУНИТЕТОМ, В ТКАНЯХ СЛЕПЫХ ОТРОСТКОВ КИШЕЧНИКА И ПОДЖЕЛУДОЧНОЙ ЖЕЛЕЗЫ ЦЫПЛЯТ-БРОЙЛЕРОВ (Gallus gallus L.) ПРИ ЭКСПЕРИМЕНТАЛЬНОМ Т-2 ТОКСИКОЗЕ*}

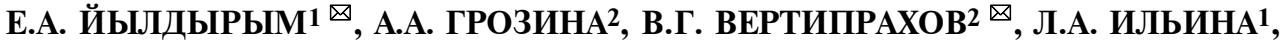

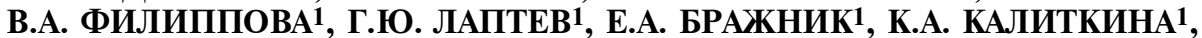 \\ Н.В. ТАРЛАВИН ${ }^{1}$, А.В. ДУБРОВИН ${ }^{1}$, Н.И. НОВИКОВА ${ }^{1}$, Д.Г. ТЮРИНА ${ }^{1}$
}

\begin{abstract}
Значительная часть кормов для сельскохозяйственной птицы загрязнена Т-2 токсином. У птиц иммунная система представляет собой одну из мишеней для этого микотоксина. Однако результаты изучения действия Т-2 токсина на изменение функциональной активности генов, связанных с иммунной системы, у птиц крайне ограничены. В представляемом исследовании мы впервые показали, что активация в тканях поджелудочной железы генов регуляторных молекул развития воспалительной реакции (IL6 и PTGS2), генов, связанных с клеточной гибелью (Casp6), а также генов антимикробных факторов (прежде всего $A v B D 10)$ может служить ранним прогностическим маркером Т-2 токсикоза у бройлеров. Цель работы заключалась в оценке влияния Т-2 токсина на экспрессию вовлеченных в реакции иммунной системы генов в тканях слепых отростков кишечника и поджелудочной железы. Из бройлеров кросса Смена 8 сформировали четыре группы: I - контрольная, птица получала рацион без добавления T-2 токсина, II - получала рацион с добавлением Т-2 токсина в количестве 100 мкг/кг (1ПДК), ІІІ - 200 мкг/кг (2ПДК), III опытная - 400 мкг/кг (4ПДК) (виварий ФНЦ ВНИТИП РАН, 2020 год). Длительность эксперимента - с 30- до 50-суточного возраста птицы, основной рацион соответствовал требованиям по кормлению кросса с учетом возраста. Анализировали активность генов, ассоциированных с воспалительной реакцией, апоптозом, а также с антимикробной и антивирусной защитой, - интерлейкина 6 IL6, интерлейкина $8 I L 8$, интерферона 7 IRF7, простагландинэндопероксид-синтазы 2 (циклооксигеназы) PTGS2, $\beta$-дефензина 9 AvBD9 (Gal9), $\beta$-дефензина 10 $A v B D 10$ (Gallo) и каспазы 6 Casp6. Референсным служил ген белка бета-актина ACTB. Режим и условия ПЦР-амплификации соответствовали предложенным разработчиками праймеров. Относительный уровень экспрессии оценивали с использованием метода $2^{-\Delta \Delta C t}$. Для сопоставления экспрессии генов и биохимических показателей крови применили метод анализа главных компонент (РСА). Полученные нами данные свидетельствуют о модуляции экспрессии генов, ассоциированных с иммунитетом, в изученных тканях под воздействием Т-2 токсина. При экспериментальном Т-2 токсикозе у бройлеров активировалась $(p \leq 0,05)$ экспрессия генов провоспалительного цитокина IL6 и гена PTGS2 циклооксигеназы, участвующей в регуляции воспаления. Это может иметь неблагоприятные последствия для здоровья и продуктивности птицы, поскольку гиперпродукция провоспалительных цитокинов вовлечена в патогенез ряда заболеваний. Усиление (до 41,7-кратного, $\mathrm{p}=0,0005$ ) экспрессии гена PTGS2 в поджелудочной железе по сравнению с контролем наблюдалось во всех опытных группах. Также во всех опытных группах в тканях слепых отростков кишечника экспрессия гена Casp6, ассоциированного с фактором апоптоза, снижалась (максимально в 12,5 раза, $\mathbf{p}=0,02$ ) по сравнению с контролем. В тканях поджелудочной железы наблюдалось, наоборот, резкое повышение экспрессии гена Casp6 при увеличении концентрации Т-2 токсина в кормах (р $\leq 0,0008)$. Во II группе экспрессия повышалась в 22,4 раза $(p=0,0008)$, в III группе - в 715,8 раза $(p=0,0003)$, в IV - в 31288,3 раза $(p=0,0003)$ по сравнению с контролем. В тканях слепых отростков кишечника бройлеров из III и IV групп экспрессия генов $A v B D 9$ и $A v B D 10$ снижалась по сравнению с контролем в 2,1-5,3 раза (р $\leq 0,05)$. В тканях поджелудочной железы, напротив, экспрессия этих генов во всех опытных группах значительно активировалась по сравнению с контролем (р $\leq 0,04)$. $A v B D 9$ и $A v B D 10-$ это гены, ассоциированные у птиц с синтезом $\beta$-дефензинов, которые связаны с усилением бактериостатической активности в отношении многих патогенов. В слепых отростках кишечника бройлеров из II группы происходило 3 -кратное $(\mathrm{p}=\mathbf{0 , 0 3})$ угнетение экспрессии гена IRF7 по сравнению с контролем. Это может иметь негативные последствия для организма, поскольку ген IRF7 связан с синтезом регуляторного фактора интерферона 7, участвующего в противовирусной защите. В целом ткани поджелудочной железы оказались намного более чувствительны к воздействию Т-2 токсина, так как экспрессия практически всех исследованных генов значительно усиливалась по сравнению с таковой в тканях слепых отростков кишечника. Обращает на себя внимание повышение частоты апоптоза, с которым тесно связана активация каспазы, в тканях поджелудочной железы. Эта разница в выраженности иммунного ответа может быть обусловлена функцинальным отличием кишечника от поджелудочной железы. С применением метода главных компо-
\end{abstract}

* Работа выполнена при поддержке гранта РНФ № 20-76-10003.

664 
нент (РСА) было продемонстрировано, что уровень экспрессии генов PTGS2 в поджелудочной железе, IL6, PTGS2, IL8, IRF7, AvBD9, AvBD10 и Casp6 в слепых отростках кишечника бройлеров, а также содержание в крови общего белка, глюкозы, триглицеридов, активность щелочной фосфатазы и трипсина и соотношение активности этих ферментов находились в тесной взаимосвязи. Активация вовлеченных в развитие воспалительной реакции генов IL6 и PTGS2 в тканях поджелудочной железы, генов, связанных с клеточной гибелью, например Casp6, а также антимикробных факторов, прежде всего $A v B D 10$, может служить ранним прогностическим маркером T-2 токсикоза у бройлеров. Уровень экспрессии таких генов может быть количественным показателем дозы воздействия и потенциального эффекта Т-2 токсина, а также чувствительности бройлеров к этому токсиканту при мониторинге рисков Т-2 токсикоза.

Ключевые слова: Т-2 токсин, микотоксикоз, бройлеры, экспрессия генов, иммунитет, цитокины, интерферон, апоптоз, $\beta$-дефензины.

Значительная часть кормов для птицы, прежде всего, фуражного зерна, загрязнена микотоксинами - вторичными продуктами жизнедеятельности микроскопических грибов. Среди них Т-2 токсин признан одним из наиболее токсичных (1). Это соединение относится к сесквитерпеноидным трихотеценовым микотоксинам, продуцируемым плесневыми грибами родов Fusarium, Myrothecium, Cephalosporium, Verticimonosporium и Stachybotrys. Микромицеты Fusarium spp. - основные продуценты Т-2 токсина и наиболее распространенные патогены сельскохозяйственных культур в умеренном климате Европы, Азии, Северной Америки (2). В России продемонстрирована широкая распространенность Т-2 токсина в комбикормовом сырье (зернофураже, жмыхе, шротах) и в полнорационных комбикормах для сельскохозяйственной птицы $(3,4)$, получены данные о высокой частоте загрязнения Т-2 токсином подсолнечного шрота и подсолнечного жмыха (5).

Токсичность фузариевых микотоксинов основана на способности связываться с рибосомами эукариот и ингибировать синтез белка, а также способности к образованию свободных радикалов (6). В результате воздействия Т-2 токсина на животных отмечено изменение метаболизма в тканях селезенки, тимуса, желудка и печени (7).

У птицы при загрязнении кормов Т-2 токсином отмечают отказ от корма, ухудшение показателей его конверсии, кровавую диарею, снижение прироста живой массы, яйценоскости, истончение скорлупы яиц (8). Действию микотоксинов в наибольшей степени подвержена эпителиальная поверхность пищеварительного тракта $(9,10)$, что проявляется в язвеннонекротическом воспалении. У других животных при воздействии Т-2 токсина также отмечали ацинарную дегенерацию и некроз в поджелудочной железе (11).

В ряде исследований $(12,13)$ подтверждена гипотеза о том, что иммунная система - одна из мишеней микотоксинов. Трихотеценовые микотоксины разнонаправленно и с неодинаковой интенсивностью действуют на разные звенья иммунитета, проявляя как иммуностимулирующие, так и иммуносупрессивные свойства в зависимости от дозы и частоты воздействия. Пищеварительному тракту присуща функция региональной иммунной системы $(14,15)$. В тканях слизистой оболочки, выстилающей желудочно-кишечный тракт, находятся лимфоидные структуры, которые представляют собой первую линию защиты от патогенов и ксенобиотиков, попадающих в организм (15). У птиц лимфоидные ткани в желудочно-кишечном тракте хорошо развиты и состоят из собственно лимфоидных клеток, а также специализированных лимфоидных структур Пейеровых бляшек (16). Эти структуры играют важную роль в индукции иммунных реакций (17). Клетки эпителия слизистой оболочки пищеварительной системы птиц снабжены TLR-рецепторами, связанными с индукцией синтеза хемокинов, цитокинов, лизоцимов, $\beta$-дефензинов, кателици- 
динов, авидина (18-20). У кур описаны провоспалительные цитокины интерлейкин-1 $\beta$ (IL1B), интерлейкин-6 (IL6), интерлейкин-17 (IL17A), интерлейкин-22 (IL22) (21). Из основных групп антимикробных пептидов дефензинов у кур выявлена $\beta$-дефензины (ранее были известны как галлинацины) AvBD1 (Gal1, Gal1), AvBD2 (Gal2), AvBD4 (Gal4), AvBD10 (Gal10) (22-24). Благодаря конформации $\beta$-дефензины птиц проявляют более выраженную эффективность в отношении грамположительных бактерий (25). Ключевую роль в апоптозе играют ферменты каспазной группы. Помимо апоптоза, эти ферменты участвуют в модуляции воспалительных реакций (26).

Таким образом, отравления микотоксинами, в частности Т-2 токсином, могут сопровождаться осложнениями, связанными с нарушением биологических механизмов резистентности к инфекциям и других иммунных функций. Объем исследований таких изменений растет $(1,27)$, однако сведения о влиянии Т-2 токсина на экспрессию генов, ассоциированных с иммунитетом, у птиц остаются крайне ограниченными. Накопление этих данных позволит понять закономерности нарушений иммунного гомеостаза, что необходимо для поиска эффективных иммуностимуляторов или иммунодепрессантов для профилактики и лечения постинтоксикационных инфекционных осложнений и заболеваний и выявления биомаркеров Т-2 токсикоза.

В настоящей работы мы впервые показали, что экспрессия некоторых генов, связанных с иммунитетом, служит ранним прогностическим маркером Т-2 токсикоза у бройлеров. Это касается активации в тканях поджелудочной железы генов регуляторных молекул, обеспечивающих начальные этапы развития воспалительной реакции, в частности IL6 и PTGS2, а также генов, связанные с клеточной гибелью, например Casp6. Кроме того, маркером патологического процесса может быть активация генов антимикробных факторов, прежде всего $A v B D 10$.

Цель исследования заключалась в оценке влияние 20-суточного воздействия Т-2 токсина при внесении с кормами на экспрессию генов, ассоциированных с воспалительной реакцией, апоптозом, антимикробной и антивирусной защитой.

Meтодика. Эксперименты проводили на цыплятах-бройлерах ( Gallus gallus L.) кросса Смена 8 в период с 30- до 50-суточного возраста (виварий ФНЦ ВНИТИП РАН, 2020 год) в соответствии с требованиями Европейской конвенции о защите позвоночных животных, используемых для экспериментов или в иных научных целях (ETS № 123, Страсбург, 1986). Условия кормления и содержания соответствовали требованиям для кросса («Методика проведения научных и производственных исследований по кормлению сельскохозяйственной птицы. Молекулярногенетические методы определения микрофлоры кишечника». Сергиев Посад, 2013).

Основу рациона птицы составлял комбикорм ПК-6 (Россия). Корм механически контаминировали стандартным Т-2 токсином (порошок с

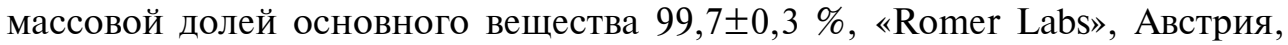
cat. N 10000310, LOT \#S17052T) до задаваемой ПДК с соблюдением требований безопасности персонала. Количество микотоксинов в корме до контаминации (фоновое содержание) и после контаминации контролировали методом тандемной высокоэффективной жидкостной хроматомасс-спектрометрии (ВЭЖХ-МС/МС); хроматографическая система Agilent 1260 Infinity LC, («Agilent Technologies», США), масс-спектрометр AB SCIEX Triple Quad ${ }^{\mathrm{TM}} 5500$ («Sciex», CША), колонка для обращенно- 
фазового разделения Gemini ${ }^{\circledR} \mathrm{C} 18$ 110A $5 \mu \mathrm{m}$ 150×4,6 mm («Phenomenex», США). Хроматографическое разделение проводили в режиме бинарного градиентного элюирования. При приготовлении подвижных фаз А и Б и проведении ВЭЖХ-МС/МС руководствовались ГОСТ 34140-2017 «Продукты пищевые, корма, продовольственное сырье. Метод определения микотоксинов с помощью высокоэффективной жидкостной хроматографии с масс-спектрометрическим детектированием» (М., 2020). Режим разделения: 1,5 мин - $100 \%$ элюента A, 1,5 мин - линейное увеличение доли элюента Б до $50 \%, 9$ мин - линейное увеличение доли элюента Б до 100 \%, 5 мин - хроматографическое разделение при 100 \% элюента Б; температура колонки $25{ }^{\circ} \mathrm{C}$, скорость потока подвижной фазы $1 \mathrm{~cm}^{3} /$ мин, температура ввода проб $10{ }^{\circ} \mathrm{C}$, объем пробы 5 мм $^{3}$. Время удерживания для $\mathrm{T}$ 2 токсина - 10,30 мин, для НТ-2 токсина - 9,79 мин. Пределы обнаружения - 3,25 мкг/кг для Т-2 токсина и 2,70 мкг/кг для НТ-2 токсина, пределы количественного определения для Т-2 токсина - 5,23-129,20 мкг/кг, для НТ-2 токсина - 3,50-129,20 мкг/кг. Расчетный ион (в режиме положительной ионизации распылением в электрическом поле) для Т-2 токсина $-305,1 \mathrm{~m} / \mathrm{z}$, для НТ-2 токсина $-345,1 \mathrm{~m} / \mathrm{z}$. Для построения калибровочных графиков и в качестве внутренних стандартов использовали стандартные растворы Т-2 и НТ-2-токсина серии Biopure («Romer Labs», Австрия).

Цыплят разделили на четыре группы (по 5 гол. в каждой): I группа получала рацион без введения Т-2 токсина (контроль), II - рацион с добавлением Т-2 токсина в количестве 100 мкг/кг (1ПДК), III - 200 мкг/кг (2ПДК), IV - 400 мкг/кг (4ПДК).

Для анализа экспрессии генов у бройлеров в конце эксперимента отбирали ткани слепых отростков кишечника и поджелудочной железы. Образцы стабилизировали с помощью фиксатора IntactRNA для стабилизации РНК в биологических образцах (ЗАО «Евроген», Россия). Ткани гомогенизировали в жидком азоте. Для выделения тотальной РНК использовали мини-набор Aurum ${ }^{\mathrm{TM}}$ Total RNA («Bio-Rad Laboratories, Inc.», США), следуя инструкциям производителя. Реакцию обратной транскрипции проводили с использованием iScript ${ }^{\mathrm{TM}}$ Reverse Transcription Supermix («Bio-Rad Laboratories, Inc.», США) (28).

Для анализа экспрессии были выбраны семь генов. Специфические пары праймеров: для IL6 F - 5'AGGACGAGATGTGCAAGAAGTTC-3', $\quad$ R TTGGGCAGGTTGAGGTTGTT-3'; для IL8 F - 5'-GGAAGAGAGGTGTGCTTGGA-3', R - 5'-TAACATGAGGCACCGATGTG-3'; для IRF7 $\mathrm{F} \quad-\quad 5^{\prime}$-ATCCCTTGGAAGCACAACGCC-3', R - 5'CTGAGGCAACCGCG-TAGACCTT-3'; для PTGS2 F $\quad$ - 5 5'TCGAGATCACACTTGATTGACA-3'; $\quad \mathrm{R} \quad-\quad$ 5'TTTGTGCCTTGTGGGTCAG-3'; для AvBD9 (Gal9) F — 5'-AACACCGTCAGGCATCTTCACA-3'， R - 5'-CGTCTTCTTGGCTGTAAGCTGGA-3'; для $A v B D 10$ (Gal10) F - 5'-GCTCTTCGCTGTTCTCCTCT-3', R - 5'-CCAGAGATGGTGAAGGTG-3', для Casp6 F - 5'-CAGAGGAGACAAGTGCCAGA-3', $\mathrm{R}$ - 5'-CCAGGAGCCGTTTACAGTTT-3'. В качестве референсного контроля использовали ген «домашнего хозяйства» $A C T B$ (белок бета-актина) с праймерами F - 5'-ATTGTCCACCGCAAATGCTTC3', R - 5'-AAATAAA-GCCATGCCAATCTCGTC-3'.

ПЦР проводили с использованием детектирующего амплификатора ДТ Lite-4 (ООО «НПО ДНК-Технология», Россия) и набора SsoAdvanced ${ }^{\mathrm{TM}}$ 
Universal SYBR® Green Supermix («Bio-Rad Laboratories, Inc.», США) в соответствии с протоколом производителя (29). Режим и условия амплификации соответствовали каждому праймеру (30). Относительный уровень экспрессии оценивали методом $2^{-} \Delta \mathrm{CT}(31)$.

Кровь для биохимического анализа (2-3 мл) отбирали в конце эксперимента после 14-часового голодания птиц) из подкрыльцовой вены на внутренней стороне крыла над локтевым сочленением («Общие и специальные методы исследования крови птиц промышленных кроссов». Екатеринбург-Санкт-Петербург, 2009). В качестве антикоагулянта использовали цитрат натрия. Исследования выполняли на полуавтоматическом биохимическом анализаторе Sinnowa BS3000P («SINNOWA Medical Science \& Tech-nology Co., Ltd», Китай) с набором ветеринарных диагностических реагентов («ДИАКОН-ВЕТ», Россия).

Для сопоставления уровней экспрессии генов и биохимических показателей крови использовали метод главных компонент (РСА) с построением корреляционной матрицы. Число значимых главных компонент определяли на основе критерия собственного значения, равного 1, с сохранением любого компонента с собственным значением > 1 (32). Качество представления переменных на факторной карте и общий вклад в главные компоненты отдельных признаков оценивали на основании вычисления $\cos ^{2}$. Визуализацию $\cos ^{2}$ для переменных во всех измерениях проводили с помощью пакета corrplot (https://cran.rproject.org/web/packages/corrplot/corr-plot.pdf; https://github.com/taiyun/corrplot).

Математическую и статистическую обработку результатов осуществляли методом многофакторного дисперсионного анализа (multifactor ANOVA) в программах Microsoft Excel XP/2003, R-Studio (Version 1.1.453) (https://rstudio.com). Представлены средние (M) и стандартные ошибки средних $( \pm \mathrm{SEM})$. Средние значения сравнивались с использованием критерия достоверно значимой разницы Тьюки с использованием функции TukeyHSD в пакете R Stats Package (https://cran.rproject.org/web/packages/TukeyC/Tu-keyC.pdf,

https://github.com/jcfaria/TukeyC); различия считали статистически значимыми при $\mathrm{p} \leq 0,05$.

Результаты. Потребление корма бройлерами составляло в среднем 150 г/сут, то есть птица II-IV групп ежесуточно получали с кормом T-2 токсин в количестве соответственно 15, 30 и 60 мкг/гол.

В используемых для заражения кормах мы не обнаружили афлатоксинов $\left(\mathrm{B}_{1}, \mathrm{G}_{1}\right)$, фумонизинов $\left(\mathrm{B}_{1}, \mathrm{~B}_{2}, \mathrm{~B}_{3}\right)$, дезоксиниваленола (ДОН). Т-2 токсин присутствовал в фоновом количестве 4,33 мкг/кг, что не могло существенно повлиять на результаты эксперимента, учитывая, что ПДК по Т-2 токсину составляет 100 мкг/кг. Также в количествах, которые были намного меньше ПДК, были выявлены охратоксин А (2,27 мкг/кг при ПДК 50 мкг/кг) и зеараленон (2,25 мкг/кг при ПДК 1000 мкг/кг).

На рисунке 1 показано влияние Т-2 токсина на экспрессию генов интерлейкинов $I L 6, I L 8$, а также эндопероксидсинтазы простагландинов PTGS2, которые ассоциированы с провоспалительными факторами. Т-2 токсин в концентрации 100 мкг/кг (1ПДК) не повлиял на экспрессию генов IL6, IL8 и PTGS2 в слепых отростках кишечника во II группе бройлеров. Однако в III группе (2ПДК Т-2 токсина) экспрессия гена PTGS2 усиливалась в 3,0 раза (p =0,03), а в IV группе (4ПДК Т-2 токсина) эффект был еще более выражен: уровень экспрессии PTGS2 возрос в 5,9 раза (p = 0,001), кроме того, повысился уровень экспрессии гена IL6 по сравнению 
с контролем $(\mathrm{p}=0,005)$. В тканях поджелудочной железы эффект воздействия Т-2 токсина был более выраженным, чем в тканях слепых отростков кишечника. Например, повышение экспрессии гена PTGS2 (до 41,7кратного, $\mathrm{p}=0,0005)$ наблюдалось во всех опытных группах по сравнению с контрольной. Т-2 токсин специфическим образом действовал на экспрессию провоспалительных генов у бройлеров, поскольку влияния на ген IL8 (в отличие от генов IL6 и PTGS2) мы не выявили (р >0,05). В целом для влияния Т-2 токсина на экспрессию провоспалительных генов в тканях слепых отростков кишечника бройлеров отмечали очевидный дозазависимый эффект. Ранее подобный эффект в отношении IL6 при воздействии на организм животных токсических веществ был продемонстрирован S. Brown с соавт. (33).
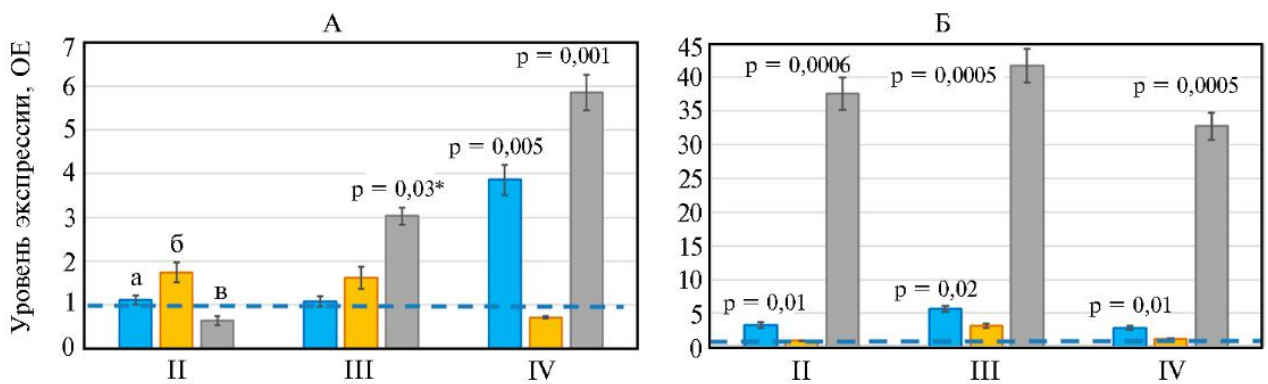

Рис. 1. Уровень экспрессии генов, ассоциированных с провоспалительными факторами, в тканях эпителия слепых отростков кишечника (А) и поджелудочной железы (Б) у цыплт-бройлеров (Gallus gallus L.) кросса Смена 8 при экспериментальном T-2 токсикозе: II, III, IV - группы, получавшие соответственно 1ПДК, 2ПДК и 4ПДК Т-2 токсина (1ПДК - 100 мкг/кг корма); а, б, в - соответственно гены IL6, IL8 и PTGS2. OЕ - кратность изменений экспрессии по сравнению с I (контрольной) группой, где уровень экспрессии принят за 1. Прерывистая синяя линия показывает уровень экспрессии в контроле. Результаты представлены как $M \pm \mathrm{SEM} \mathrm{(виварий} \mathrm{ФНЦ} \mathrm{ВНИТИП} \mathrm{РАН,} 2020$ год).

* Различия с контролем статистически значимы при $\mathrm{p} \leq 0,05$.

Активация экспрессии провоспалительных генов при скармливании Т-2 токсина может иметь неблагоприятные последствия для здоровья и продуктивности бройлеров. С одной стороны, интерлейкины имеют важное значение для врожденных защитных иммунных ответов, привлекая дополнительные лейкоциты к месту инфекции, что повышает сопротивление эпителиальных клеток $(34,35)$. С другой стороны, гиперпродукция провоспалительных цитокинов вовлечена в патогенез ряда заболеваний у животных и человека (36), а также имеет связь со снижением продуктивности сельскохозяйственных животных (37). Показано (38-40), что введение здоровым животным препаратов на основе цитокинов провоцировало негативные реакции организма. Активация воспалительных цитокинов тесно связана с экспрессией гена $P T G S 2$, поскольку цитокины способны индуцировать этот ген (41). PTGS2 - ген эндопероксидсинтазы простагландинов (циклооксигеназы 2), участвующей в окислительном превращение арахидоновой кислоты в простагландин, которая в этих реакциях также метаболизируется до биологически активных простациклина и тромбоксана А2. Простагландин, простациклин и тромбоксан А2 принимают участие как в местных, так и в системных воспалительных реакциях (42).

Наши данные, свидетельствуюшие об активации экспрессии провоспалительных генов при скармливании Т-2 токсина бройлерам, перекликаются с результатами предыдущих исследований. Показано (43-45), что под влиянием токсических веществ у животных повышается выработ- 
ка провоспалительных факторов, в частности цитокинов IL4, IL 10 и IL 13. Отмечалось (46), что воздействие трихотеценовых микотоксинов способно транскрипционно и посттранскрипционно усиливать экспрессию генов, связанных с воспалительной реакцией.

На рисунке 2 представлен уровень экспрессии гена Casp6, ассоциированного с фактором апоптоза, в тканях эпителия пищеварительной системы бройлеров в ответ на скармливание Т-2 токсина. В тканях слепых отростков кишечника во всех группах по сравнению с контролем отмечали снижение (до 12,5-кратного, $\mathrm{p}=0,02$ ) экспрессии гена Casp6 (рис. 2). Был выявлен дозозависимый эффект: увеличение концентрации токсина в корме приводило к более выраженному угнетению экспрессии. В тканях поджелудочной железы наблюдалась обратная тенденция. При повышении концентрации Т-2 токсина в кормах экспрессия гена Casp6 резкого увеличивалась ( $\mathrm{p} \leq 0,0008)$ : во II группе - в 22,4 раза $(\mathrm{p}=0,0008)$, в III - в 715,8 раза $(\mathrm{p}=0,0003)$, в IV группе - в 31288,3 раза $(\mathrm{p}=0,0003)$ по сравнению с контролем.
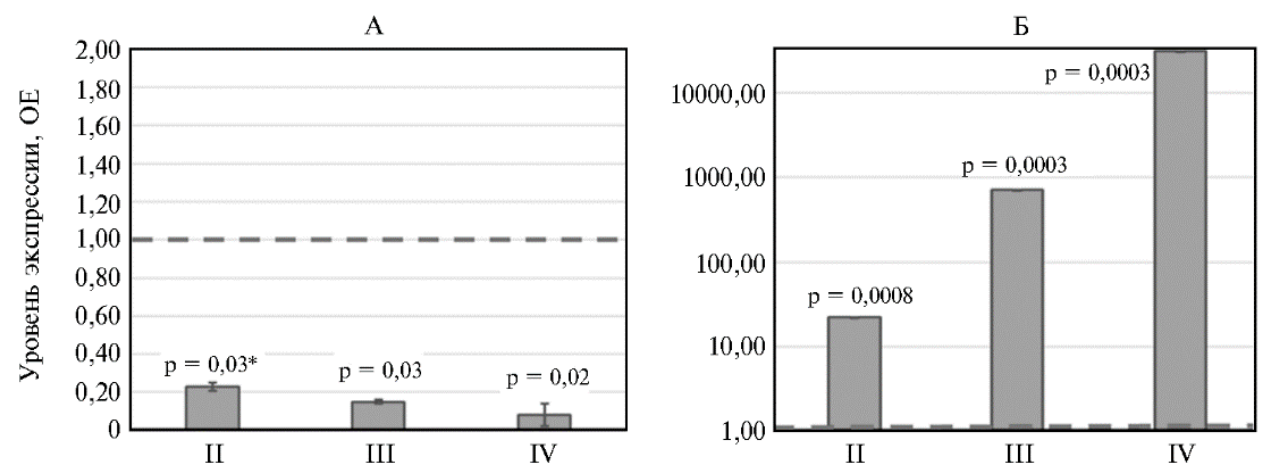

Рис. 2. Уровень экспрессии гена Саsp6, ассоциированного с фактором апоптоза, в тканях эпителия слепых отростков кишечника (А) и поджелудочной железы (Б) у цыплят-бройлеров (Gallus gallus L.) кросса Смена 8 при экспериментальном T-2 токсикозе: II, III, IV - группы, получавшие соответственно 1ПДК, 2ПДК и 4ПДК Т-2 токсина (1ПДК - 100 мкг/кг корма). ОЕ - кратность изменений экспрессии по сравнению с I (контрольной) группой, где уровень экспрессии принят за 1. Прерывистая линия показывает уровень экспрессии в контроле. Результаты представлены как $M \pm \mathrm{SEM}$ (виварий ФНЦ ВНИТИП РАН, 2020 год).

* Различия с контролем статистически значимы при $\mathrm{p} \leq 0,05$.

Casp6 - ген белка каспазы 6, который принадлежит к семейству цистеин-аспартат-специфических протеаз, активация которых играет центральную роль в клеточном апоптозе (47). С одной стороны, апоптоз (генетически запрограммированная клеточная гибель) служит важнейшим механизмом иммунорегуляции от момента созревания и дифференцировки иммунокомпетентных клеток до этапа реализации механизмов врожденного и адаптивного иммунитета $(48,49)$. С другой стороны, в тканях пищеварительной системы апоптоз, индуцированный токсинами, имеет негативные последствия, поскольку связан с повреждением митохондрий и высвобождением из них цитохрома С (митохондриально-опосредованный путь апоптоза) (50-52). Кроме того, токсические вещества могут оказывать цитотоксическое действие на макрофаги и моноциты (52-54). Активация представителей семейства каспаз способна индуцировать повреждение ДНК в макрофагах через расщепление фермента поли[АДФрибоза]полимераза 1 (РARP-1) $(52,55)$. Исследования показали, что некоторые токсические вещества инициируют апоптоз В-клеток, что может усугубить состояние иммунной системы (56). 
Полученные нами результаты, демонстрирующие активацию экспрессии гена Casp6 в поджелудочной железе бройлеров при воздействии Т-2 токсина, совпадают с данными, опубликованными ранее. Сообщалось об активации нескольких каспаз под влиянием трихотеценов (57-59). Показано (47), что высокие дозы трихотеценовых микотоксинов провоцируют апоптоз лейкоцитов с сопутствующим подавлением иммунитета. Введение грызунам in vivo трихотеценов, в том числе Т-2 токсина, приводило к апоптозу в тимусе, селезенке и костном мозге $(60,61)$.

На рисунке 3 показан уровень экспрессии генов $A v B D 9$ и $A v B D 10$ в слепых отростках кишечника и поджелудочной железе бройлеров при воздействии Т-2 токсина. AvBD9 (Gal9) и AvBD10 (Gal10) - гены $\beta$ дефен-зинов птиц (62). Дефензины, селективно рекрутируя моноциты, Тлимфоциты, незрелые дендритные и тучные клетки в очаги инфекции, участвуют в реакциях адаптивного иммунитета (63-65). Дефензины связаны с усилением бактериостатической активности в отношении многих патогенов, включая Klebsiella typhimurium, Streptococcus bovis, Enterococcus faecalis, Salmonella typhimurium (24). В тканях слепых отростков кишечника у бройлеров III и IV групп уровень экспрессии генов $A v B D 9$ и $A v B D 10$ снижался в 2,1-5,3 раза ( $\mathrm{p} \leq 0,05)$ по сравнению с контролем (см. рис. 3 ). В тканях поджелудочной железы у бройлеров из всех групп, напротив, экспрессия этих генов (особенно $A v B D 10$ ) значительно усиливалась по сравнению с контролем ( $\leq 0,04)$. Так, в IV группе мы отмечали 40,8-кратную активацию экспрессии гена $A v B D 10$ (
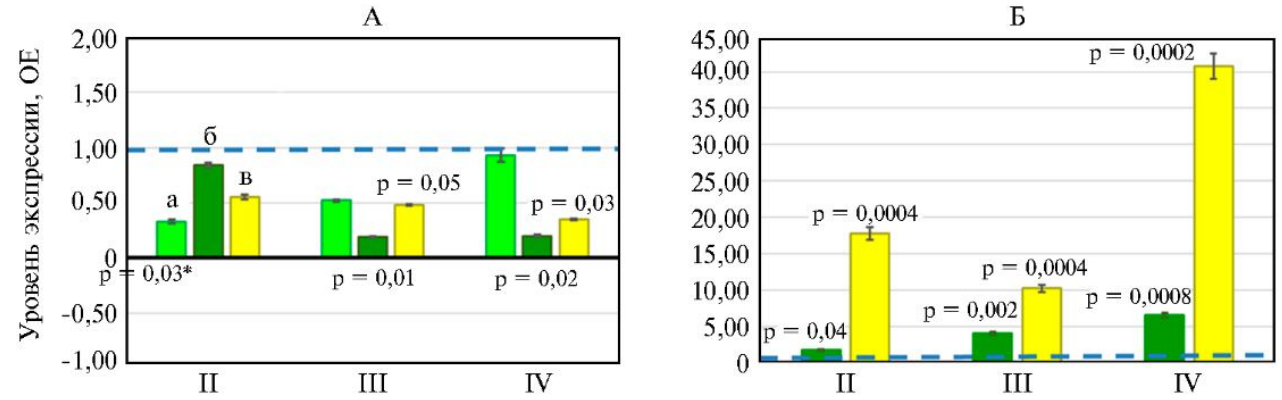

Рис. 3. Уровень экспрессии генов, ассоциированных с антимикробными и антивирусными факторами, в тканях эпителия слепых отростков кишечника (А) и поджелудочной железы (Б) у цыплят-бройлеров (Gallus gallus L.) кросса Смена 8 при экспериментальном T-2 токсикозе: II, III, IV - группы, получавшие соответственно 1ПДК, 2ПДК и 4ПДК Т-2 токсина (1ПДК 100 мкг/кг корма); а, б, в - соответственно гены IRF7, $A v B D 9$ и $A v B D 10$. ОЕ - кратность изменений экспрессии по сравнению с I (контрольной) группой, где уровень экспрессии принят за 1. Прерывистая линия показывает уровень экспрессии в контроле. Результаты представлены как $M \pm \mathrm{SEM}$ (виварий ФНЦ ВНИТИП РАН, 2020 год).

* Различия с контролем статистически значимы при $\mathrm{p} \leq 0,05$.

Отметим, что способность как понижать, так и повышать устойчивость животных к патогенам описана многими исследователями для разных микотоксинов. Цыплята-бройлеры, получавшие корма, загрязненные охратоксинами, оказались восприимчивее к заражению сальмонеллой (66). В другой работе (67) введение в корм бройлеров охратоксина А не повлияло на численность $S$. typhimurium в слепой кишке, однако синергетический эффект сальмонеллы и токсина привел к росту смертности птицы на 13,2 \% и снижению массы тела. У свиней с загрязнением кормов фумонизином $\mathrm{B}_{1}$ было связано усиление колонизации кишечника патогенной Escherichia coli (68), а при скармливании Т-2 токсина в содержимом кишечника и других органах снижалось обилие Salmonella typhimurium по 
сравнению с контролем (корм без экспериментальной контаминации Т-2 токсином) (69).

Кроме того, в слепых отростках кишечника бройлеров из II группы экспрессия гена $I R F 7$ угнеталась в 3,0 раза $(\mathrm{p}=0,03)$ по сравнению с контролем (см. рис. 3). Ген IRF7 кодирует регуляторный фактор интерферона 7 (член семейства регуляторных факторов транскрипции интерферона) (70). Благодаря своей ключевой роли в иммунитете хозяина IRF7 участвует в противодействии многим вирусам с помощью различных стратегий $(71,72)$. О результатах, подобных нашим в отношении экспрессии гена IRF7 в тканях слепых отростков кишечника цыплят-бройлеров при экспериментальном Т-2 токсикозе, сообщали J.J. Pestka с соавт. (46): скармливание цып-лятам-бройлерам смеси микотоксинов, включая ДОН, снижало синтез мРНК IFN- $\gamma$. В то же время на примере свиней (73) показано повышение продукции интерферона- $\gamma$ при загрязнении корма ДОН.

Выполненное нами сравнение эффекта Т-2 токсина в отношении экспрессии генов, связанных с иммунитетом, в тканях слепых отростков кишечника в сравнении с поджелудочной железой позволяет предположить, что ткани поджелудочной железы более чувствительны к Т-2 токсину, так как экспрессия практически всех изученных генов здесь была значительно усилена по сравнению с таковой в тканях слепых отростков кишечника. Прежде всего это касается активации в тканях поджелудочной железы генов регуляторных молекул, обеспечивающих начальные этапы развития воспалительной реакции, в число которых входят IL6 и PTGS2, генов, связанных с клеточной гибелью, например Casp6, и синтезом антимикробных факторов, особенно $A v B D 10$. Мы полагаем, что такая разница в выраженности иммунного ответа может быть следствием функциональных различий кишечника и поджелудочной железы. Показано (74), что эндокринная, как и экзокринная части поджелудочной железы обладают огромной функциональной пластичностью, что также могло внести вклад в усиление экспрессии исследованных генов при воздействии Т-2 токсина. Нашими исследованиями подтверждаются данные L. Scaglia с соавт. (75), которые описали активный апоптоз в островках Лангерганса в поджелудочной железе 13-17-суточных крыс. Апоптоз островковых клеток индуцируют аутоиммунные цитокины, в частности IL1 $\beta$ и TNFa, что связано с дополнительным высвобождением инсулина (76). Возможно, Т-2 токсин способен повлиять на синтез экзокринных пищеварительных ферментов ацинарными клетками или синтез пептидов инсулоцитами островков Лангерганса поджелудочной железы. Обнаружено, что соматостатин, вырабатываемый дельта-клетками панкреатических островков, существенно влияет на экспрессию генов, вовлеченных в воспалительные реакции и лейкоцитарный хемотаксис (77). Т-2 токсин также мог вызывать повреждение ацинарных клеток у бройлеров (11) и, как следствие, усиление экспрессии по сравнению со слепыми отростками кишечника. Есть сведения, что повреждение ацинарных клеток сопровождается усилением синтеза провоспалительных цитокинов IL6, IL1 $\beta$, TNF $\alpha$, IL8 (78).

С целью поиска факторов, оказавших влияние на экспрессию генов, ассоциированных с иммунитетом, при экспериментальном Т-2 токсикозе бройлеров, мы сопоставили данные по IL6, IL8, PTGS2, IRF7, $A v B D 9, A v B D 10$ и Casp6 в слепых отростках кишечника и поджелудочной железе с биохимическими показателями крови (общий белок, трипсин, глюкоза, щелочная фосфатаза, холестерин, триглицериды, соотношение ФПИ - щелочная фосфатаза/трипсин) (табл.), использовав метод главных компонент (РСА) (рис. 4).

672 
Биохимические показатели крови у цыплят-бройлеров (Gallus gallus L.) кросса

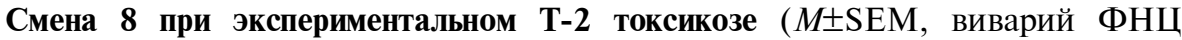
ВНИТИП РАН, 2020 год)

\begin{tabular}{|c|c|c|c|c|}
\hline \multirow{2}{*}{ Показатель } & \multicolumn{4}{|c|}{ Группа $(n=5)$} \\
\hline & I (контрольная) & II (1ПДК) & III (2ПДК) & IV (4ПДК) \\
\hline \multirow{3}{*}{ Общий белок, г/л } & $39,5 \pm 0,83$ & $36,8 \pm 1,94$ & $39,9 \pm 0,17$ & $41,5 \pm 1,31$ \\
\hline & $40,1 \pm 0,71$ & $40,3 \pm 1,23$ & $40,4 \pm 0,19$ & $41,4 \pm 0,16$ \\
\hline & $36,3 \pm 1,20$ & $36,4 \pm 0,13$ & $35,5 \pm 0,21$ & $40,1 \pm 0,85^{b}$ \\
\hline \multirow{4}{*}{ Трипсин, ед/л } & $74.2 \pm 3.17$ & $60,3 \pm 1,52$ & $62,6 \pm 0,68$ & $67,5 \pm 4,51$ \\
\hline & $93.3 \pm 4,36^{\mathrm{a}}$ & $82,0 \pm 1,58^{\mathrm{ab}}$ & $82,5 \pm 1,12^{\mathrm{ab}}$ & $72,6 \pm 0,31^{b}$ \\
\hline & $77,5 \pm 6,43$ & $68,6 \pm 3,02$ & $60,4 \pm 3,89$ & $66,3 \pm 7,65$ \\
\hline & & & \multicolumn{2}{|c|}{ Продолжение таблицы } \\
\hline \multirow[t]{3}{*}{ Глюкоза, ммоль/л } & $12,1 \pm 0,19$ & $11,1 \pm 0,32$ & $11,1 \pm 0,13$ & $10,9 \pm 0,09^{\mathrm{b}}$ \\
\hline & $12,4 \pm 0,24$ & $11,2 \pm 0,33$ & $12,8 \pm 0,07$ & $13,0 \pm 0,21^{\mathrm{a}}$ \\
\hline & $10,4 \pm 0,32^{\mathrm{a}}$ & $9,8 \pm 0,16^{\mathrm{a}}$ & $10,0 \pm 0,16^{\mathrm{a}}$ & $9,0 \pm 0,31^{\mathrm{a}}$ \\
\hline Щелочная фосфатаза & $6232 \pm 590,7$ & $5456 \pm 313,1$ & $7974 \pm 621,2$ & $8157 \pm 296,5$ \\
\hline \multirow[t]{2}{*}{ (ЩФ), ед/л } & $4179 \pm 456,1^{\mathrm{a}}$ & $4310 \pm 609,7$ & $4370 \pm 476,2^{\mathrm{a}}$ & $2987 \pm 757,8^{a b}$ \\
\hline & $1298 \pm 192,5^{\mathrm{a}}$ & $754 \pm 37,7 \mathrm{ab}$ & $1303 \pm 118,8^{a}$ & $3695 \pm 114,7 \mathrm{ab}$ \\
\hline \multirow[t]{3}{*}{ Холестерин, ммоль/л } & $2,9 \pm 0,09$ & $3,0 \pm 0,12$ & $3,3 \pm 0,23$ & $3,5 \pm 0,12$ \\
\hline & $3,4 \pm 0,04$ & $3,1 \pm 0,05$ & $3,6 \pm 0,25$ & $3,6 \pm 0,21$ \\
\hline & $2,8 \pm 0,14$ & $3,1 \pm 0,60$ & $3,1 \pm 0,26$ & $2,8 \pm 0,04$ \\
\hline \multirow[t]{3}{*}{ Триглицериды, ммоль/л } & $0,4 \pm 0,01$ & $0,3 \pm 0,01$ & $0,3 \pm 0,02$ & $0,4 \pm 0,02$ \\
\hline & $0,3 \pm 0,01$ & $0,3 \pm 0,02$ & $0,4 \pm 0,02$ & $0,4 \pm 0,28$ \\
\hline & $0,8 \pm 0,04 \mathrm{a}$ & $0,4 \pm 0,02$ & $0,4 \pm 0,15$ & $0,2 \pm 0,01^{\mathrm{a}}$ \\
\hline \multirow[t]{3}{*}{ ФПИ (ЩФ/трипсин) } & 83,9 & 90,5 & 127,4 & 120,8 \\
\hline & 44,8 & 52,6 & 52,9 & 41,1 \\
\hline & 16,7 & 10,9 & 21,6 & 55,7 \\
\hline
\end{tabular}
средняя - 40-суточный возраст (получали Т-2 токсин в течение 7 сут), нижняя -47 -суточный возраст (получали Т-2 токсин 14 сут); контрольная группа Т-2 токсин не получала; 1ПДК - 100 мкг/кг корма.

а Различия между показателями у цыплят разного возраста статистически значимы при $\mathrm{p}<0,05$.

b Различия между показателями у контрольных цыплят и цыплят, получавших Т-2 токсин в разных дозах, статистически значимы при $\mathrm{p}<0,05$.

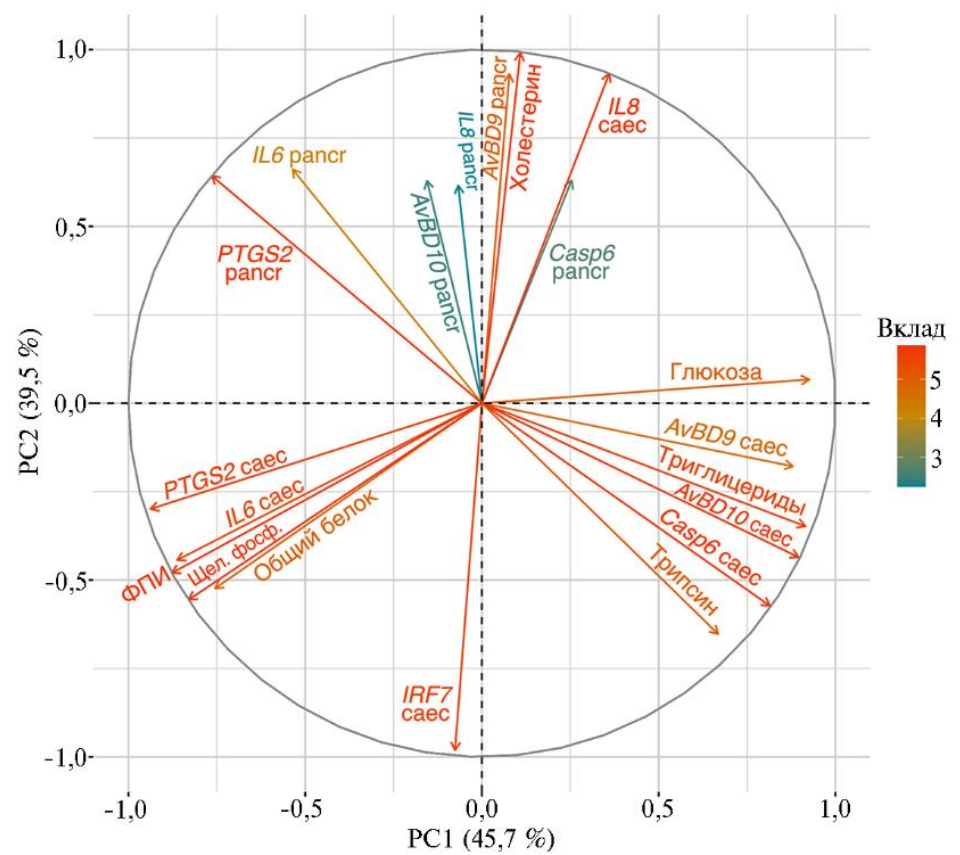

Рис. 4. Факторная карта (метод главных компонент РСА), основанная на значениях экспрессии генов, связанных с иммунитетом, в тканях (pancr - поджелудочная железа, саес - слепые отростки кишечника) и биохимических показателях крови у цыплят-бройлеров (Gallus gallus L.) кросса Смена 8 при экспериментальном T-2 токсикозе. Градиент цвета и близость к кругу корреляций отражают вклад переменных в основные компоненты: красный цвет и близость к кругу корреляций означает высокий вклад, синий цвет и удаленность от круга корреляций означает низкий вклад. Переменная, находящаяся по одну сторону с другой переменной, имеет высокое значение для этой переменной, а находящаяся на диаметрально противополож- 
ной стороне от другой переменной имеет низкое значение для такой переменной. ФПИ соотношение щелочная фосфатаза/трипсин (виварий ФНЦ ВНИТИП РАН, 2020 год).

Рисунок 5 характеризует качество представленных переменных $\left(\cos ^{2}\right)$ на факторной карте (см. рис. 4). Переменные, включающие значения экспрессии генов PTGS2 в поджелудочной железе, IL6, PTGS2, IL8, IRF7, $A v B D 9, A v B D 10$ и Casp6 в слепых отростках кишечника, а также данные по общему белку, трипсину, глюкозе, щелочной фосфатазе, триглицеридах, ФПИ в крови бройлеров внесли высокий вклад в PC1 co значением соs² 0,44-0,88 (см. рис. 4, 5).

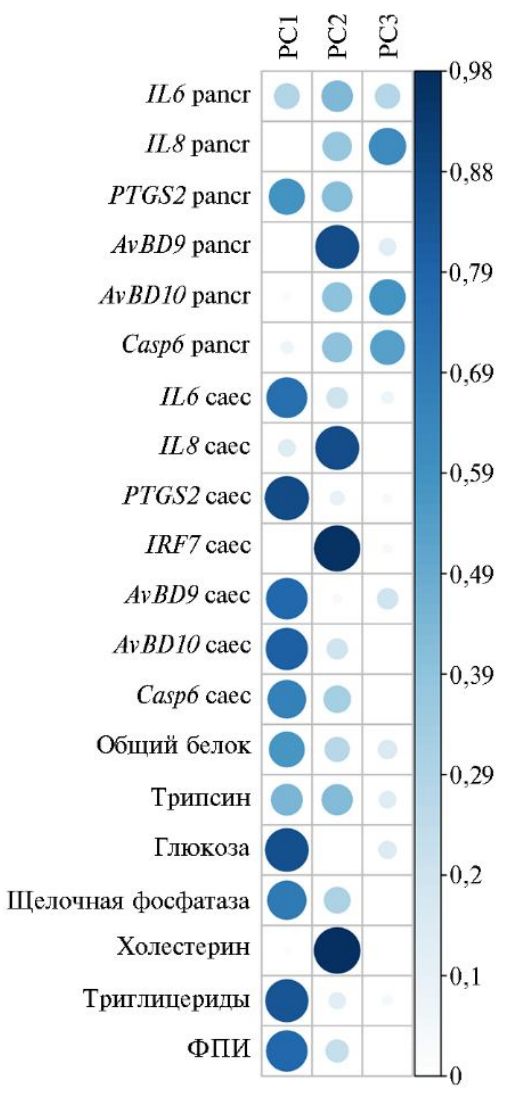

Рис. 5. Визуализация качества представленных переменных $\left(\cos ^{2}\right)$ на факторной карте (см. рис. 4, метод главных компонент РСА) для экспрессии генов, связанных с иммунитетом, в тканях (pancr - поджелудочная железа, саес - слепые отростки кишечника) и биохимических показателей крови у цыплят-бройлеров (Gallus gallus L.) кросса Смена 8 при экспериментальном T-2 токсикозе (построено с помощью пакета corrplot (https://cran.rproject.org/web/packages/corrplot/corrplot.pdf;

https://github.com/taiyun/corrplot). Диаметр окружности и интенсивность цвета отражают вклад переменных $\left(\cos ^{2}\right)$ в главные компоненты: большой диаметр и темно-синий цвет (высокий $\cos ^{2}$ ) указывают на высокий вклад переменной, отсутствие окружности и белый цвет (низкий $\cos ^{2}$ ) - на самый низкий вклад (виварий ФНЦ ВНИТИП РАН, 2020 год).

Полученные результаты свидетельствуют о том, что изученные показатели находились в тесной связи друг с другом, что представляется закономерным. Так, было показано (79) изменение активности пищеварительных ферментов у бройлеров при воздействии теплового стресса и связанное с этим изменение синтеза мРНК некоторых генов, в частности SGLT1, GLUT2, FABP1. В опытах по экспериментальной гиперстимуляции острого панкреатита у животных $(80,81)$ обнаружили, что воспалительные заболевания поджелудочной железы связаны с активацией синтеза трип-

сина в ацинарных клетках. Следовательно, изменение синтеза трипсина при загрязнении корма бройлеров Т-2 токсином могло внести вклад в регуляцию экспрессии провоспалительных генов, в частности PTGS2. Кроме того, сообщалось (82), что трипсин вовлечен в образование в органеллах так называемых «хрупких» мембран, через которые катепсин В и другие ферменты проникают в цитозоль. Высвободившийся катепсин В индуцирует апоптоз (посредством активации каспаз) и гибель ацинарных клеток поджелудочной железы (82). В другом исследовании (83) было показано, что протеасомы, обеспечивающие деградацию белков в клетках, содержат два трипсиноподобных и два каспазоподобных протеолитических участка, для которых доказаны сложные взаимодействия: субстраты каспазоподобных сайтов аллостерически ингибируют химотрипсиноподобную активность. Эти факты проясняют причину выявленной нами взаимосвязи между экспрессией гена Casp6 и содержанием трипсина в крови. 
Экспрессия генов IL6, AvBD9 в поджелудочной железе, IL8, IRF7 в слепых отростках кишечника и содержание холестерина в крови бройлеров внесли высокий вклад в РС2 со значением $\cos ^{2} 0,44-0,98$ (см. рис. 4, 5). Полученные нами результаты указывают на взаимовлияние этих переменных. Действительно, сообщалось (84), что ген $I L 8$, активируя экспрессию гена miR-183 в макрофагах, который, в свою очередь, ингибирует экспрессию гена $A B C A 1$, вмешивается в $A B C A 1$-зависимый отток холестерина. В другой работе (85) обнаружено, что высокий уровень внутриклеточного холестерина играет решающую роль в передаче сигналов, инициируемых продуктом провоспалительного гена $I L-17 A$ в кератиноцитах.

Результаты нашего исследования показывают, что повышенные уровни экспрессии генов, контролирующих защитные реакции организма и определяющих характер иммунологических реакций при воздействии Т2 токсина, можно рассматривать как ранние прогностические маркеры Т-2 токсикоза у бройлеров. Прежде всего это активации в тканях поджелудочной железы генов регуляторных молекул, которые вовлечены в начальные этапы развития воспалительных реакций (IL6 и PTGS2), генов, связанных с клеточной гибелью (Casp6), генов антимикробных факторов (прежде всего $A v B D 10$ ).

Итак, полученные нами данные свидетельствуют о воздействии загрязнения кормов бройлеров Т-2 токсином на иммунные функции слепых отростков кишечника и поджелудочной железы через модуляцию экспрессии генов, связанных с иммунитетом. Наблюдаемая активация (p $\leq 0,05)$ экспрессии провоспалительных генов IL6 и PTGS2 может создавать риски для здоровья птицы и снижать ее продуктивность, поскольку гиперпродукция провоспалительных цитокинов вовлечена в патогенез различных заболеваний. В поджелудочной железе экспрессия гена PTGS2 усиливалась даже при 1ПДК Т-2 токсина в корме, достигая 41,7-кратных значений по сравнению с контролем ( $=0,0005)$. В тканях слепых отростков кишечника снижалась экспрессия гена фактора апоптоза Casp6, начиная с 1ПДК (до 12,5-кратного уменьшения, $\mathrm{p}=0,02$ ), а в поджелудочной железе, наоборот, активность гена Casp6 при повышении концентрации Т-2 токсина в кормах резко возрастала (в 22,4-31288,3 раза, $\mathrm{p} \leq 0,0008$ ). При 2ПДК и 4ПДК Т-2 токсина в тканях слепых отростков кишечника экспрессии генов $\beta$-дефензинов $A v B D 9$ и $A v B D 10$ снижалась по сравнению с контролем (в 2,1-5,3 раза, $\mathrm{p} \leq 0,05)$, а в поджелудочной железе (независимо от дозы Т-2 токсина) - наоборот, усиливалась $(\mathrm{p} \leq 0,04)$ при всех использованных ПДК (в большей степени это касалось $A v B D 10$ ). В слепых отростках кишечника птиц при 1ПДК Т-2 токсина экспрессия гена IRF7, связанного с проявлением противовирусной активности, подавлялась в 3,0 раза $(\mathrm{p}=0,03)$. В целом в тканях поджелудочной железы заметнее активировалась экспрессия практически всех исследованных генов, ассоциированных с иммунитетом, а также значительно повышалась частота апоптоза, с которым тесно связана активация каспазы. То есть поджелудочная железа оказалась чувствительнее к Т-2 токсину, чем ткани слепых отростков кишечника, что может быть связано с функциональными различиями кишечника и поджелудочной железы. Анализ методом главных компонент (PCA) показал, что экспрессия генов PTGS2 в поджелудочной железе, IL6, $P T G S 2, I L 8, I R F 7, A v B D 9, A v B D 10$ и Casp6 в слепых отростках кишечника, а также уровень общего белка, трипсина, глюкозы, щелочной фосфатазы, триглицеридов, соотношение щелочная фосфатаза/трипсин в крови бройлеров находились в тесной взаимосвязи. Повышенные уровни экспрессии генов IL6, PTGS2, Casp6, AvBD10 могут рассматриваться в качестве марке- 
ров развития Т-2 токсикоза у бройлеров и использоваться для количественной характеристики потенциального эффекта Т-2 токсина и оценки чувствительности птицы к нему при мониторинге состояния поголовья и проведении профилактических и лечебных мероприятий в птицехозяйствах.

\section{ЛИТЕРАТУРА}

1. Adhikari M., Negi B., Kaushik N., Adhikari A., Al-Khedhairy A.A., Kaushik N.K., Ha Choi E. T-2 mycotoxin: toxicological effects and decontamination strategies. Oncotarget, 2017, 16(8): 33933-33952 (doi: 10.18632/oncotarget.15422).

2. Creppy E.E. Update of survey, regulation and toxic effects of mycotoxins in Europe. Toxicology Letters, 2002, 127(1-3): 19-28 (doi: 10.1016/s0378-4274(01)00479-9).

3. Безбородова Н.А. Мониторинг микотоксинов в кормах и кормовом сырье и клиникоиммуно-логические особенности микотоксикозов животных в Уральском регионе. Автореф. канд. дис. Екатеринбург, 2009.

4. Гогина Н.Н. Мониторинг содержания микотоксинов в кормах, поступивших в испытательный центр внитип в период с 2012 по 2014 годы. Mатериалы XVIII Международной конференции Всемирной научной ассоциации по птицеводству (Российское отделение) «Инновационное обеспечение яичного и мясного птицеводства России». НП «Научный центр по птицеводству», п. Ржавки, 2015: 127-129.

5. Кононенко Г.П., Буркин А.А., Зотова Е.В. Микотоксикологический мониторинг. Сообщение 3. Кормовая продукция от переработки зернового сырья. Ветеринария сегодня, 2020, 3(34): 213-219 (doi: 10.29326/2304-196X-2020-3-34-213-219).

6. Oswald I.P., Marin D.E., Bouhet S., Pinton P., Taranu I., Accensi F. Immunotoxicological risk of mycotoxins for domestic animals. Food Additives and Contaminants, 2005, 22(4): 354-360 (doi: 10.1080/02652030500058320).

7. Wan Q., Wu G., He Q., Tang H., Wang Y. The toxicity of acute exposure to T-2 toxin evaluated by the metabonomics technique. Molecular bioSystems, 2015, 11(3): 882-891 (doi: 10.1039/c4mb00622d).

8. Akande K.E., Abubakar M.M., Adegbola T.A., Bogoro S.E. Nutritional and health implications of mycotoxins in animal feeds: a review. Pakistan Journal of Nutrition, 2006, 5: 398-403 (doi: 10.3923/pjn.2006.398.403).

9. Maresca M., Mahfoud R., Garmy N., Fantini J. The mycotoxin deoxynivalenol affects nutrient absorption in human intestinal epithelial cells. The Journal of Nutrition, 2002, 132(9): 27232731 (doi: 10.1093/jn/132.9.2723).

10. Sergent T., Parys M., Garsou S., Pussemier L., Schneider Y.-J., Larondelle Y. Deoxynivalenol transport across human intestinal Caco-2 cells and its effects on cellular metabolism at realistic intestinal concentrations. Toxicology Letters, 2006, 164(2): 167-176 (doi: 10.1016/j.toxlet.2005.12.006).

11. Pang V.F., Adams J.H., Beasley V.R., Buck W.B., Haschek W.M. Myocardial and pancreatic lesions induced by T-2 toxin, a trichothecene mycotoxin, in swine. Veterinary Pathology, 1986, 23(3): 310-319 (doi: 10.1177/030098588602300312).

12. Seeboth J., Solinhac R., Oswald I.P., Guzylack-Piriou L. The fungal T-2 toxin alters the activation of primary macrophages induced by TLR-agonists resulting in a decrease of the inflammatory response in the pig. Veterinary Research, 2012, 43(1): 35 (doi: 10.1186/1297-971643-35).

13. Pierron A., Alassane-Kpembi I., Oswald I.P. Impact of mycotoxin on immune response and consequences for pig health. Animal nutrition (Zhongguo xu mu shou yi xue hui), 2016, 2(2): 6368 (doi: 10.1016/j.aninu.2016.03.001).

14. Oswald I.P. Role of intestinal epithelial cells in the innate immune defence of the pig intestine. Veterinary Research, 2006, 37(3): 359-368 (doi: 10.1051/vetres:2006006).

15. Nochi T., Jansen C.A., Toyomizu M., van Eden W. The well-developed mucosal immune systems of birds and mammals allow for similar approaches of mucosal vaccination in both types of animals. Frontiers in Nutrition, 2018, 5: 60 (doi: 10.3389/fnut.2018.00060).

16. Casteleyn C., Doom M., Lambrechts E., Van den Broeck W., Simoens P., Cornillie P. Locations of gut-associated lymphoid tissue in the 3-month-old chicken: a review. Avian Pathology, 2010, 39(3): 143-150 (doi: 10.1080/03079451003786105).

17. Bar-Shira E., Sklan D., Friedman A. Establishment of immune competence in the avian GALT during the immediate post-hatch period. Developmental and Comparative Immunology, 2003, 27(2): 147-157 (doi: 10.1016/s0145-305x(02)00076-9).

18. Goitsuka R., Chen C.-L.H., Benyon L., Asano Y., Kitamura D., Cooper M.D. Chicken 
cathelicidin-B1, an antimicrobial guardian at the mucosal M cell gateway. Proceedings of the National Academy of Sciences of the United States of America, 2007, 104(38): 15063-15068 (doi: 10.1073/pnas.0707037104).

19. Nile C.J., Townes C.L., Michailidis G., Hirst B.H., Hall J. Identification of chicken lysozyme g2 and its expression in the intestine. Cellular and Molecular Life Sciences, 2004, 61(21): 27602766. (doi: 10.1007/s00018-004-4345-z).

20. Cuperus T., van Dijk A., Dwars R.M., Haagsman H.P. Localization and developmental expression of two chicken host defense peptides: cathelicidin-2 and avian $\beta$-defensin 9. Developmental and Comparative Immunology, 2016, 61: 48-59 (doi: 10.1016/j.dci.2016.03.008).

21. Gibson M.S., Kaiser P., Fife M. The chicken IL-1 family: evolution in the context of the studied vertebrate lineage. Immunogenetics, 2014, 66(7-8): 427-438 (doi: 10.1007/s00251-0140780-7).

22. Klotman M.E., Chang T.L. Defensins in innate antiviral immunity. Nature Reviews Immunology, 2006, 6(6): 447-456 (doi: 10.1038/nri1860).

23. Lynn D.J., Higgs R., Gaines S., Tierney J., James T., Lloyd A.T., Fares M.A., Mulcahy G., O'Farrelly C. Bioinformatic discovery and initial characterisation of nine novel antimicrobial peptide genes in the chicken. Immunogenetics, 2004, 56(3): 170-177 (doi: 10.1007/s00251004-0675-0).

24. Yacoub H.A., Elazzazy A.M., Abuzinadah O.A.H., Al-Hejin A.M., Mahmoud M.M., Harakeh S.M. Antimicrobial activities of chicken $\beta$-defensin (4 and 10) peptides against pathogenic bacteria and fungi. Frontiers in Cellular and infection Microbiology, 2015, 5: 36 (doi: 10.3389/fcimb.2015.00036).

25. Cuperus T., Coorens M., van Dijk A., Haagsman H.P. Avian host defense peptides. Developmental and Comparative Immunology, 2013, 41(3): 352-369 (doi: 10.1016/j.doi.2013.04.019).

26. Kapczuk P., Kosik-Bogacka D., Kupnicka P., Metryka E., Simi ska D., Rogulska K., Skyrka M., Gutowska I., Chlubek D., Baranowska-Bosiacka I. The influence of selected gastrointestinal parasites on apoptosis in intestinal epithelial cells. Biomolecules, 2020, 10(5): 674 (doi: 10.3390/biom10050674).

27. Xue C.Y., Wang G.H., Chen F., Zhang X.B., Bi Y.Z., Cao Y.C. Immunopathological effects of ochratoxin A and T-2 toxin combination on broilers. Poultry Science, 2010, 89(6): 1162-1166 (doi: 10.3382/ps.2009-00609).

28. Zeka F., Vanderheyden K., Smet E., Cuvelier C., Mestdagh P., Vandesompele J. Straightforward and sensitive RT-qPCR based gene expression analysis of FFPE samples. Scientific Reports, 2016, 6: 21418 (doi: 10.1038/srep21418).

29. Meza Cerda M.I., Gray R., Higgins D.P. Cytokine RT-qPCR and ddPCR for immunological investigations of the endangered Australian sea lion (Neophoca cinerea) and other mammals. PeerJ, 2020, 8: e10306 (doi: 10.7717/peerj.10306).

30. Laptev G.Y., Filippova V.A., Kochish I.I., Yildirim E.A., Ilina L.A., Dubrovin A.V., Brazhnik E.A., Novikova N.I., Novikova O.B., Dmitrieva M.E., Smolensky V.I., Surai P.F., Griffin D.K., Romanov M.N. Examination of the expression of immunity genes and bacterial profiles in the caecum of growing chickens infected with Salmonella enteritidis and fed a phytobiotic. Animals, 2019, 9(9): 615 (doi: 10.3390/ani9090615).

31. Livak K.J., Schmittgen T.D. Analysis of relative gene expression data using real-time quantitative PCR and the 2- ${ }^{-} \mathrm{CT}$ method. Methods, 2001, 25(4): 402-408 (doi: 10.1006/meth.2001.1262).

32. Jolliffe I.T. Principal component analysis. Springer series in statistics. New York, Springer-Verlag, 2002 (doi: 10.1007/b98835).

33. Brown S., Wilburn W., Martin T., Whalen M. Butyltin compounds alter secretion of interleukin 6 from human immune cells. Journal of Applied Toxicology, 2018, 38(2): 201-218 (doi: 10.1002/jat.3514).

34. Moldawer L.L., Gelin J., Scherstŭn T., Lundholm K.G.. Circulating interleukin 1 and tumor necrosis factor during inflammation. The American Journal of Physiology, 1987, 253(6): 922-928 (doi: 10.1152/ajpregu.1987.253.6.R922).

35. Cannon J.G., Tompkins R.G., Gelfand J.A., Michie H.R., Stanford G.G., van der Meer J.W., Endres S., Lonnemann G., Corsetti J., Chernow B. Circulating IL-1 and TNF in septic shock and experimental endotoxin fever. Journal of Infectious Diseases, 1990, 161(1): $79-84$ (doi: 10.1093/infdis/161.1.79).

36. Lotze A.T.M. The cytokine handbook. Academic Press, 2003.

37. Broom L.J., Kogut M.H. Inflammation: friend or foe for animal production? Poultry Science, 2018, 97(2): 510-514. (doi: 10.3382/ps/pex314).

38. Moldawer L.L., Andersson C., Gelin J., Lundholm K.G. Regulation of food intake and hepatic protein synthesis by recombinant-derived cytokines. American Journal of Physiology, 1988, 254(3): 450-456 (doi: 10.1152/ajpgi.1988.254.3.G450).

39. Tracey K.J., Wei H., Manogue K.R., Fong Y., Hesse D.G., Nguyen H.T., Kuo G.C., Beutler B., Cotran R.S., Cerami A. Cachectin/tumor necrosis factor induces cachexia, anemia, 
and inflammation. Journal of Experimental Medicine, 1988, 167(3): 1211-1227 (doi: 10.1084/jem.167.3.1211).

40. Fong Y., Moldawer L.L., Marano M., Wei H., Barber A., Manogue K., Tracey K.J., Kuo G. Cachectin/TNF or IL-1 alpha induces cachexia with redistribution of body proteins. American Journal of Physiology, 1989, 256(3-Pt 2): R659-665 (doi: 10.1152/ajpregu.1989.256.3.R659).

41. Prescott S.M., Fitzpatrick F.A. Cyclooxygenase-2 and carcinogenesis. Biochimica et Biophysica Acta, 2000, 1470(2): 69-78 (doi: 10.1016/s0304-419x(00)00006-8).

42. Thuresson E.D., Lakkides K.M., Rieke C.J., Sun Y., Wingerd B.A., Micielli R., Mulichak A.M., Malkowski M.G., Garavito R.M., Smith W.L. Prostaglandin Endoperoxide H Synthase-1: the functions of cyclooxygenase active site residues in the binding, positioning, and oxygenation of arachidonic acid 210. Journal of Biological Chemistry, 2001, 276(13): 1034710357 (doi: 10.1074/jbc.M009377200).

43. Yan H., Takamoto M., Sugane K. Exposure to Bisphenol A prenatally or in adulthood promotes $\mathrm{T}(\mathrm{H}) 2$ cytokine production associated with reduction of CD4CD25 regulatory $\mathrm{T}$ cells. Environmental Health Perspectives, 2008, 116(4): 514-519 (doi: 10.1289/ehp.10829).

44. Kuo C.-H., Hsieh C.-C., Kuo H.-F., Huang M.-Y., Yang S.-N., Chen L.-C., Huang S.-K., Hung C.-H. Phthalates suppress type I interferon in human plasmacytoid dendritic cells via epigenetic regulation. Allergy, 2013, 68(7): 870-879 (doi: 10.1111/all.12162).

45. Feng Y., Tian J., Xie H.Q., She J., Xu S.L., Xu T., Tian W., Fu H., Li S., Tao W., Wang L., Chen Y., Zhang S., Zhang W., Guo T.L., Zhao B. Effects of acute low-dose exposure to the chlorinated flame retardant Dechlorane 602 and Th1 and Th2 immune responses in adult male mice. Environmental Health Perspectives, 2016, 124(9): 1406-1413 (doi: 10.1289/ehp.1510314).

46. Pestka J.J., Zhou H.-R., Moon Y., Chung Y.J. Cellular and molecular mechanisms for immune modulation by deoxynivalenol and other trichothecenes: unraveling a paradox. Toxicology Letters, 2004, 153(1): 61-73 (doi: 10.1016/j.toxlet.2004.04.023).

47. Alnemri E.S., Livingston. D.J., Nicholson D.W., Salvesen G., Thornberry N.A., Wong W.W., Yuan J. Human ICE/CED-3 protease nomenclature. Cell, 1996, 87: 171 (doi: 10.1016/s00928674(00)81334-3).

48. Krammer P.H. CD95's deadly mission in the immune system. Nature, 2000, 407(6805): 789795 (doi: 10.1038/35037728).

49. Savino W., Dardenne M. Neuroendocrine control of thymus physiology. Endocrine Reviews, 2000, 21(4): 412-443 (doi: 10.1210/edrv.21.4.0402).

50. Lv Q.-Y., Wan B., Guo L.-H., Zhao L., Yang Y. In vitro immune toxicity of polybrominated diphenyl ethers on murine peritoneal macrophages: apoptosis and immune cell dysfunction. Chemosphere, 2015, 120: 621-630 (doi: 10.1016/j.chemosphere.2014.08.029).

51. Wu B., Guo H., Cui H., Peng X., Fang J., Zuo Z., Deng J., Wang X., Huang J. Pathway underlying small intestine apoptosis by dietary nickel chloride in broiler chickens. Chemicobiological Interactions, 2016, 243: 91-106 (doi: 10.1016/j.cbi.2015.11.010).

52. Huang F.-M., Chang Y.-C., Lee S.-S., Ho Y.-C., Yang M.-L., Lin H.-W., Kuan Y.-H. Bisphenol A exhibits cytotoxic or genotoxic potential via oxidative stress-associated mitochondrial apoptotic pathway in murine macrophages. Food and Chemical Toxicology, 2018, 122: 215-224 (doi: 10.1016/j.fct.2018.09.078).

53. Hwang J.K., Min K.H., Choi K.H., Hwang Y.C., Jeong I.-K., Ahn K.J., Chung H.-Y., Chang J.S. Bisphenol A reduces differentiation and stimulates apoptosis of osteoclasts and osteoblasts. Life Sciences, 2013, 93(9-11): 367-372 (doi: 10.1016/j.lfs.2013.07.020).

54. Neri M., Virzì G.M., Brocca A., Garzotto F., Kim J.C., Ramponi F., de Cal M., Lorenzin A., Brendolan A., Nalesso F., Zanella M., Ronco C. In vitro cytotoxicity of Bisphenol A in monocytes cell line. Blood Purification, 2015, 40(2): 180-186 (doi: 10.1159/000437039).

55. Mokra K., Kocia M., Michałowicz J. Bisphenol A and its analogs exhibit different apoptotic potential in peripheral blood mononuclear cells (in vitro study). Food and Chemical Toxicology, 2015, 84: 79-88 (doi: 10.1016/j.fct.2015.08.007).

56. Baker A.H., Wu T.H., Bolt A.M., Gerstenfeld L.C., Mann K.K., Schlezinger J.J. From the cover: tributyltin alters the bone marrow microenvironment and suppresses B cell development. Toxicological Sciences, 2017, 158(1): 63-75 (doi: 10.1093/toxsci/kfx067).

57. Miura K., Aminova L., Murayama Y. Fusarenon-X induced apoptosis in HL-60 cells depends on caspase activation and cytochrome c release. Toxicology, 2002, 172(2): 103-112 (doi: 10.1016/s0300-483x(01)00586-8).

58. Nagase M., Shiota T., Tsushima A., Murshedul Alam M., Fukuoka S., Yoshizawa T., Sakato N. Molecular mechanism of satratoxin-induced apoptosis in HL-60 cells: activation of caspase-8 and caspase-9 is involved in activation of caspase-3. Immunology Letters, 2002, 84(1): 23-27 (doi: 10.1016/s0165-2478(02)00127-x).

59. Pae H.O., Oh G.S., Choi B.M., Seo E.A., Oh H., Shin M.K., Kim T.H., Kwon T.O., Chunga H.T. Induction of apoptosis by 4-acetyl-12,13-epoxyl-9-trichothecene-3,15-diol from Isaria japonica Yasuda through intracellular reactive oxygen species formation and caspase- 3 activation in human leukemia HL-60 cells. Toxicology in vitro, 2003, 17(1): 49-57 (doi: 10.1016/s08872333(02)00097-8). 
60. Ihara T., Yamamoto T., Sugamata M., Okumura H., Ueno Y. The process of ultrastructural changes from nuclei to apoptotic body. Virchows Archiv, 1998, 433(5): 443-447 (doi: $10.1007 / \mathrm{s} 004280050272)$.

61. Islam Z., Nagase M., Ota A., Ueda S., Yoshizawa T., Sakato N. Structure-function relationship of T-2 toxin and its metabolites in inducing thymic apoptosis in vivo in mice. Bioscience, Biotechnology, and Biochemistry, 1998, 62(8): 1492-1497 (doi: 10.1271/bbb.62.1492).

62. van Dijk A., Veldhuizen E.J.A., Haagsman H.P. Avian defensins. Veterinary Immunology and Immunopathology, 2008, 124(1-2): 1-18 (doi: 10.1016/j.vetimm.2007.12.006).

63. Chertov O., Michiel D.F., Xu L., Wang J.M., Tani K., Murphy W.J., Longo D.L., Taub D.D., Oppenheim J.J. Identification of defensin-1, defensin-2, and CAP37/azurocidin as T-cell chemoattractant proteins released from interleukin-8-stimulated neutrophils. Journal of Biological Chemistry, 1996, 271(6): 2935-2940 (doi: 10.1074/jbc.271.6.2935).

64. Yang D., Chertov O., Bykovskaia S.N., Chen Q., Buffo M.J., Shogan J., Anderson M., Schrцder J.M., Wang J.M., Howard O.M., Oppenheim J.J. Beta-defensins: linking innate and adaptive immunity through dendritic and T cell CCR6. Science, 1999, 286(5439): 525-528 (doi: 10.1126/science.286.5439.525).

65. Niyonsaba F., Iwabuchi K., Matsuda H., Ogawa H., Nagaoka I. Epithelial cell-derived human beta-defensin-2 acts as a chemotaxin for mast cells through a pertussis toxin-sensitive and phospholipase C-dependent pathway. International Immunology, 2002, 14(4): 421-426 (doi: 10.1093/intimm/14.4.421).

66. Gupta S., Jindal N., Khokhar R.S., Asrani R.K., Ledoux D.R., Rottinghaus G.E. Individual and combined effects of ochratoxin A and Salmonella enterica serovar Gallinarum infection on pathological changes in broiler chickens. Avian Pathology, 2008, 37(3): 265-272 (doi: 10.1080/03079450802043759).

67. Elissalde M.H., Ziprin R.L., Huff W.E., Kubena L.F., Harvey R.B. Effect of ochratoxin A on Salmonella-challenged broiler chicks. Poultry Science, 1994, 73(8): 1241-1248 (doi: 10.3382/ps.0731241).

68. Oswald I.P., Desautels C., Laffitte J., Fournout S., Peres S.Y., Odin M., Le Bars P., Le Bars J., Fairbrother J.M. Mycotoxin fumonisin B1 increases intestinal colonization by pathogenic Escherichia coli in pigs. Applied and Environmental Microbiology, 2003, 69(10): 5870-5874 (doi: 10.1128/aem.69.10.5870-5874.2003).

69. Verbrugghe E., Vandenbroucke V., Dhaenens M., Shearer N., Goossens J., De Saeger S., Eeckhout M., D’Herde K., Thompson A., Deforce D., Boyen F., Leyman B., Van Parys A., De Backer P., Haesebrouck F., Croubels S., Pasmans F. T-2 toxin induced Salmonella typhimurium intoxication results in decreased Salmonella numbers in the cecum contents of pigs, despite marked effects on Salmonella-host cell interactions. Veterinary Research, 2012, 43(1): 22 (doi: 10.1186/1297-9716-43-22).

70. Ning S., Pagano J.S., Barber G.N. IRF7: activation, regulation, modification and function. Genes and Immunity, 2011, 12(6): 399-414 (doi: 10.1038/gene.2011.21).

71. Wang Y., Yang F., Yin H., He Q., Lu Y., Zhu Q., Lan X., Zhao X., Li D., Liu Y, Xu H. Chicken interferon regulatory factor 7 (IRF7) can control ALV-J virus infection by triggering type I interferon production through affecting genes related with innate immune signaling pathway. Developmental \& Comparative Immunology, 2021, 119(5573): 104026 (doi: 10.1016/j.dci.2021.104026).

72. Haller O., Kochs G., Weber F. The interferon response circuit: induction and suppression by pathogenic viruses. Virology, 2006, 344(1): 119-130 (doi: 10.1016/j.virol.2005.09.024).

73. Lessard M., Savard C., Deschene K., Lauzon K., Pinilla V.A., Gagnon C.A., Lapointe J., Guay F., Chorfi Y. Impact of deoxynivalenol (DON) contaminated feed on intestinal integrity and immune response in swine. Food and Chemical Toxicology, 2015, 80: 7-16 (doi: 10.1016/j.fct.2015.02.013).

74. Nascimento A.A., Sales A., Cardoso T.R.D., Pinheiro N.L., Mendes R.M.M. Immunocytochemical study of the distribuition of endocrine cells in the pancreas of the Brazilian sparrow species Zonotrichia capensis subtorquata (Swaison, 1837). Brazilian Journal of Biology, 2007, 67(4): 735-740 (doi: 10.1590/s1519-69842007000400021).

75. Scaglia L., Cahill C.J., Finegood D.T., Bonner-Weir S. Apoptosis participates in the remodeling of the endocrine pancreas in the neonatal rat. Endocrinology, 1997, 138(4): 1736-1741 (doi: 10.1210/endo.138.4.5069).

76. Petrik J., Arany E., McDonald T.J., Hill D.J. Apoptosis in the pancreatic islet cells of the neonatal rat is associated with a reduced expression of insulin-like growth factor II that may act as a survival factor. Endocrinology, 1998, 139(6): 2994-3004 (doi: 10.1210/endo.139.6.6042).

77. Adams J.M., Low M.J. Gene expression profiling reveals a possible role for somatostatin in the innate immune response of the liver. Genomics Data, 2015, 5: 42-45 (doi: 10.1016/j.gdata.2015.04.029).

78. Malmstrwm M.L., Hansen M.B., Andersen A.M., Ersbwll A.K., Nielsen O.H., Jwrgensen L.N., Novovic S. Cytokines and organ failure in acute pancreatitis: inflammatory response in 
acute pancreatitis. Pancreas, 2012, 41(2): 271-277 (doi: 10.1097/MPA.0b013e3182240552).

79. Al-Zghoul M.B., Alliftawi A.R.S., Saleh K.M.M., Jaradat Z.W. Expression of digestive enzyme and intestinal transporter genes during chronic heat stress in the thermally manipulated broiler chicken. Poultry Science, 2019, 98(9): 4113-4122 (doi: 10.3382/ps/pez249).

80. Saluja A., Saluja M., Villa A., Leli U., Rutledge P., Meldolesi J., Steer M. Pancreatic duct obstruction in rabbits causes digestive zymogen and lysosomal enzyme colocalization. Journal of Clinical Investigation, 1989, 84(4): 1260-1266 (doi: 10.1172/JCI114293).

81. Saluja A.K., Bhagat L., Lee H.S., Bhatia M., Frossard J.L., Steer M.L. Secretagogue-induced digestive enzyme activation and cell injury in rat pancreatic acini. American Journal of Physiology, 1999, 276(4): 835-842 (doi: 10.1152/ajpgi.1999.276.4.G835).

82. Dixit A., Dawra R.K., Dudeja V., Saluja A.K. Role of trypsinogen activation in genesis of pancreatitis. Pancreapedia: Exocrine Pancreas Knowledge Base, 2016 (doi: 10.3998/panc.2016.25).

83. Kisselev A.F., Garcia-Calvo M., Overkleeft H.S., Peterson E., Pennington M.W., Ploegh H.L., Thornberry N.A., Goldberg A.L. The caspase-like sites of proteasomes, their substrate specificity, new inhibitors and substrates, and allosteric interactions with the trypsin-like sites. Journal of Biological Chemistry, 2003, 278(38): 35869-35877 (doi: 10.1074/jbc.M303725200).

84. Tang X.-E., Li H., Chen L.-Y., Xia X.-D., Zhao Z.-W., Zheng X.-L., Zhao G.-J., Tang C.-K. IL-8 negatively regulates ABCA1 expression and cholesterol efflux via upregulating miR-183 in THP-1 macrophage-derived foam cells. Cytokine, 2019, 122: 154385 (doi: 10.1016/j.cyto.2018.04.028).

85. Varshney P., Narasimhan A., Mittal S., Malik G., Sardana K., Saini N. Transcriptome profiling unveils the role of cholesterol in IL-17A signaling in psoriasis. Scientific Reports, 2016, 6: 19295 (doi: 10.1038/srep19295).

$10 O О$ «БИОТРОФ+»,

192284 Россия, г. Санкт-Петербург, Загребский б-р, 19, корп. 1, e-mail: deniz@biotrof.ru $₫$, ilina@biotrof.ru,dumova@biotrof.ru, laptev@biotrof.ru, bea@biotrof.ru,kseniya.k.a@biotrof.ru, tarlav1995@biotrof.ru,dubrovin@biotrof.ru,novikova@biotrof.ru, tiurina@biotrof.ru;

2ФНЦ Всероссийский научно-исследовательский

и технологический институт птицеводства РАН,

141311 Россия, Московская обл., г. Сергиев Посад,

ул. Птицеградская, 10,

e-mail: alena_fisinina@mail.ru, Vertiprakhov63@mail.ru $₫$
Поступила в редакцию 22 апреля 2021 года

Sel'skokhozyaistvennaya biologiya [Agricultural Biology], 2021, V. 56, № 4, pp. 664-681

\title{
EFFECT OF T-2 TOXIN ON EXPRESSION OF GENES ASSOCIATED WITH IMMUNITY IN TISSUES OF THE BLIND PROCESSES OF THE INTESTINAL AND PANCREAS OF BROILERS (Gallus gallus L.)
}

\author{
E.A. Yildirim ${ }^{\natural}$, A.A. Grozina ${ }^{2}$, V.G. Vertiprakhov ${ }^{2}$, L.A. Ilyina ${ }^{1}$, V.A. Filippova ${ }^{1}$, \\ G.Yu. Laptev', E.A. Brazhnik', K.A. Kalitkinal, N.V. Tarlavin'1, A.V. Dubrovin', \\ N.I. Novikoval, D.G. Tyurina ${ }^{1}$
}

\begin{abstract}
IJSC Biotrof+, 19, korp. 1, Zagrebskii bulv., St. Petersburg, 192284 Russia, e-mail deniz@biotrof.ru ( $\square$ corresponding author), ilina@biotrof.ru, dumova@biotrof.ru, laptev@biotrof.ru, bea@biotrof.ru, kseniya.k.a@biotrof.ru, tarlav1995@biotrof.ru,dubrovin@biotrof.ru,novikova@biotrof.ru, tiurina@biotrof.ru;

${ }^{2}$ Federal Scientific Center All-Russian Research and Technological Poultry Institute RAS, 10, ul. Ptitsegradskaya, Sergiev Posad, Moscow Province, 141311 Russia,e-mail alena_fisinina@mail.ru, Vertiprakhov63@mail.ru ( corresponding author)

ORCID:

Yildirim E.A. orcid.org/0000-0002-5846-4844 Grozina A.A. orcid.org/0000-0002-3088-0454

Vertiprakhov V.G. orcid.org/0000-0002-3240-7636

Ilyina L.A. orcid.org/0000-0003-2490-6942

Filippova V.A. orcid.org/0000-0001-8789-9837

Laptev G.Yu. orcid.org/0000-0002-8795-6659
\end{abstract}

The authors declare no conflict of interests

Acknowledgements:

Supported financially from the Russian Science Foundation, grant No. 20-76-10003

Received April 22, 2021

doi: 10.15389/agrobiology.2021.4.664eng

\section{Abstract}

A significant proportion of poultry feed is contaminated with T-2 toxin. The bird's immune system is one of the targets of this xenobiotic. However, the results of studying the effect of T- 
2 toxin on the expression of immunity genes in birds are extremely limited. In the present study, we have shown that contamination of broiler feed with T-2 toxin affects the level of expression of genes associated with the functioning of the immune system in the cecum and pancreas. The aim of the work was to assess the effect of T-2 toxin on the level of expression of genes involved in the immune system responses in the tissues of the intestine and pancreas cecum in broilers. The feeding trials with T-2 toxin added to the feed were carried out on broilers of the Smena 8 cross from 30 to 50 days of age (the vivarium of the Federal Research Center VNITIP RAS, 2020). Broilers were assigned to four treatments. The control group I received a diet with no T-2 toxin added, group II received a diet added with $100 \mu \mathrm{g} / \mathrm{kg} \mathrm{T}-2$ toxin, group III with $200 \mu \mathrm{g} / \mathrm{kg}$, and group IV with 400 $\mu \mathrm{g} / \mathrm{kg}$. Gene expression was analyzed by quantitative PCR with reverse transcription (RT-qPCR). A reverse transcription reaction was performed to generate cDNA on an RNA template using the iScript $^{\mathrm{TM}}$ Reverse Transcription Supermix (Bio-Rad, USA). The following primer pairs were used: for Interleukin 6 (IL6) $\mathrm{F}-5^{\prime}$-AGGACGAGATGTGCAAGAAGTTC-3', $\mathrm{R} \quad-\quad$ 5'-TTGGGCAGGTTGAGGTTGTT-3'; for Interleukin 8 (IL8) F - 5'-GGAAGAGAGGTGTGCTTGGA-

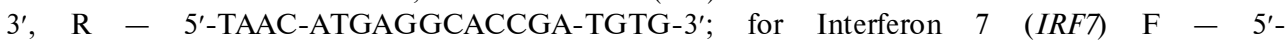
ATCCCTTGGAAGCACAACGCC-3', R - 5'-CTGA-GGCAACCGCGTAGACCTT-3'; for Prostaglandin-endoperoxide synthase 2 (PTGS2) $\mathrm{F}-5^{\prime}$-TC-GAGATCACACTTGATTGACA-3', R 5'-TTTGTGCCTTGTGGGTCAG-3'; for avian beta-defensin 9 (AvBD9(Gal9)) $\mathrm{F} \quad-\quad 5^{\prime}-$ AACACCGTCAGGCATCTTCACA-3', R - 5'-CGTCTTCTTGGCTGTAAGCTGGA-3', for avian beta-defensin $10 \quad\left(A v B D 10(\right.$ Gallo) $) \quad \mathrm{F} \quad-\quad 5^{\prime}$-GCTCTTCGCT-GTTCTCC-TCT-3', R $\quad$ - 5'CCAGAGATGGTGAAGGTG-3'; for Caspase 6 (Casp6) $\mathrm{F}-$ 5'-CAGAGGAGACAAGTGCCAGA-3', R - 5'-CCAGGAGCCGTTTACAGTTT-3'. The beta-actin protein gene was a reference control. Amplification reactions were performed using a SsoAdvanced ${ }^{\mathrm{TM}}$ Universal SYBR ${ }^{\circledR}$ Green Supermix (Bio-Rad, USA). The amplification mode and conditions corresponded to those proposed by the primer developers. The relative expression level was estimated by the 2- $\Delta \mathrm{CT}^{\mathrm{CT}}$ method. Biochemical blood profiles of broilers were analyzed (a Sinnowa BS3000P semiautomatic biochemical analyzer, SINNOWA Medical Science \& Technology Co., Ltd, China) with a set of veterinary diagnostic reagents (DIAKON-VET, Russia). Principal component analysis (PCA) was used to compare gene expression levels and blood biochemical parameters. The expression of genes associated with the inflammatory response, apoptosis, antimicrobial and antiviral protection was evaluated. Activation $(\mathrm{p} \leq 0.05)$ of the expression of the pro-inflammatory genes IL6 and PTGS2 occurred in broilers fed T-2 toxin. This can adversely affect the health and productivity of the birds, since the overproduction of proinflammatory cytokines is involved in the pathogenesis of several diseases. An increase (up to 41.7-fold, $\mathrm{p}=0.0005$ ) in the PTGS2 gene expression in the pancreas was characteristic of all groups fed T-2 toxin compared to the control. In the tissues of the intestinal cecum, there was a decrease (up to 12.5 -fold, $\mathrm{p}=0.02$ ) in the expression level of the Casp 6 gene of the apoptosis factor regardless of the T-2 toxin dosage. In the pancreas, there was a reverse tendency of a sharp increase in the Casp6 gene expression as the T-2 toxin concentration increased ( $\mathrm{p} \leq$ $0.0008)$. In group II, the expression increased 22.4 times $(\mathrm{p}=0.0008)$, in group III 715.8 times $(\mathrm{p}=$ $0.0003)$, in group IV 31288.3 times $(\mathrm{p}=0.0003)$ compared to the control. The expression of $A v B D 9$ and $A v B D 10$ genes of avian $\beta$-defensins which are associated with a higher bacteriostatic activity against many pathogens decreased 2.1 to 5.3 times $(\mathrm{p} \leq 0.05)$ in the caecum of broilers fed 200 and $400200 \mu \mathrm{g} / \mathrm{kg} \mathrm{T}-2$ toxin. In the pancreas, regardless of the T-2 toxin dosage, on the contrary, the expression of these genes significantly increased $(\mathrm{p} \leq 0.04)$. In the caecum, $100 \mu \mathrm{g} / \mathrm{kg} \mathrm{T}-2$ toxin exposure inhibited the $I R F 7$ gene expression 3 -fold $(\mathrm{p}=0.03)$ compared to the control. This can negative affect birds' health, since the IRF7 gene of the interferon regulatory factor 7 participates in counteraction against many viruses. In general, the pancreas was found to be more sensitive to the effects of the T-2 toxin because the expression of almost all studied genes was significantly increased as compared to that in the cecum tissue. This difference in the immune response may be due to the functional divergence between the intestine and the pancreas. PCA method revealed a close relationship between the expression of the PTGS2 gene in the pancreas, the IL6, PTGS2,IL8,IRF7, AvBD9, $A v B D 10$, and Casp6 genes in the cecum and the total blood protein, trypsin, glucose, alkaline phosphatase, triglycerides, and phosphatase/trypsin coefficient. Our findings indicate the effect of feed contamination with T-2 toxin on the immunological functions of the caecum and pancreas of broilers through modulation of the immunity genes expression. Quantitative PCR analysis of the expression of immunity genes can serve as an effective tool for the search for predictive markers of T-2 toxicosis of poultry to monitor the health status of livestock in poultry farms.

Keywords: T-2 toxin, mycotoxicosis, broilers, gene expression, bird immunity, cytokine, interferon, apoptosis, $\beta$-defensins. 